\title{
The effects of dietary supplements of polyunsaturated fatty acid on pearl oyster, Pinctada margaritifera L., gonad composition and reproductive output
}

\begin{abstract}
Black-lip pearl oyster, Pinctada margaritifera broodstock was collected from the wild. Egg production, hatching rate and larval development were compared between oysters induced to spawn within 2 days after collection in the wild (T1), oysters fed a pure microalgae diet during 24 days before spawning (T2) and oysters fed the same microalgal diet in which 10\% of the algae were replaced with $2 \mu \mathrm{m}$ polyunsaturated fatty acid (PUFA)-rich microspheres (T3). Administration of lipid microspheres resulted in larger sized eggs, a higher percentage of D-larvae and larger sized 48-h-old larvae $(\mathrm{P}<0.05)$. The total and neutral lipid contents of the gonad increased after oysters were fed with microalgae only or with supplementary diet. The major neutral and polar fractions of saturated fatty acid (SFA) were 16C and 18C fatty acids, and not influenced by the diet $(\mathrm{P}>0.05)$. The gonads of oysters fed supplementary PUFA contained more docosahexaenoic acid (DHA) and less monounsaturated fatty acids. Higher level of DHA in gonads of T3 was associated with oogenesis and embryogenesis success. The n-3/n-6 ratio in the neutral lipid fraction provides a good indication of the spawning condition and predicting egg size and hatching rate.
\end{abstract}

Keyword: Pinctada margaritifera, broodstock, microalgae, oogenesis, larvae, lipid 